\title{
Improving of The Army Control Effectiveness for the Geoinformation Component Automation
}

\author{
Nataliya LYTVYNENKO', Oleksiy FEDCHENKO² \\ ${ }^{1}$ Military Institute of Taras Shevchenko National University of Kyiv, Lomonosova str. 81, 03022 Kyiv, Ukraine \\ ${ }^{2}$ Military Institute of Taras Shevchenko National University of Kyiv, Lomonosova str. 81, 03022 Kyiv, Ukraine \\ E-mails: ${ }^{1} n 123 n @ u k r . n e t ;{ }^{2}$ a_fedchenko@ecomm.kiev.ua
}

\begin{abstract}
In the paper the problematic issues of the military control automation processes and improving of the control level through the introduction of the geoinformation and special information component in the military control process are shown. The improving of the quality and efficiency of the control system can be achieved by automating control, that in turn affects the combat effectiveness of the troops (forces). The implementation of the process of command and control automation requires the using a single geoinformation framework and specialized software products for geospatial data processing.
\end{abstract}

KEY WORDS: geoinformation component, special information component, geoinformation technology, army control

\section{Introduction}

The issue of improving the effectiveness of the military command in the short term is one of the most important and priority in the command system development of the Armed Forces of Ukraine. The control system is the troops command and control authorities, that is actually the control part of the system (the first level information subsystem of the complex system decomposition), that controls the executive part of the system (the first level resource subsystem of the complex system decomposition). In this case, the purposeful information function of the control part is identified with the feature of the entire information control process in the system, that also involves the executive (resource) part. The executive information function is implemented by the resource part, that "consumes" the information of combat missions and transforms it during the action of the forces (on the operational level) into the current situation information, that is "consumed" by the control part (the compliance control of the forces action process with their combat task).

One of the ways to improve the quality and efficiency of the control system is the automation of the control process, that, in turn, affects the combat effectiveness of the troops (forces) [1]. In order to implement the process of the troop control automation, it is necessary to use a single geoinformation framework and specialized software products for geospatial data processing.

\section{Investigation Results}

In modern conditions, the volume and diversity of data used in the planning, organization and conduct of the military operations has increased significantly. The composition of information required by the governing bodies and staffs in the process of their activities, is constantly updated with different types of data. In addition to data on the area, the flow of operational and tactical, reconnaissance, meteorological and geophysical information is growing, that must be analyzed and taken into account in the preparation and conduct of the operations. Even today, the required types of data in the required amounts can't be accepted, processed and integrated using existing software and hardware by the military authorities in making operational decisions on operations and the use of weapons. The amount of this information is enormous. Its transmission and processing require high-speed data transmission channels, means of the storing data in virtually unlimited volumes, computers with the capacity of tens of millions to hundreds of billions of operations per second, means of the processing and displaying graphic information, including in three-dimensional view.

\footnotetext{
${ }^{1}$ Corresponding author. Tel.: +30685932175.

E-mail address:n123n@ukr.net
} 
Compared to the Armed Forces of the leading countries of the world, the current state of providing the Armed Forces of Ukraine with terrain and objects information it is characterized by insufficient use of the huge opportunities of the information technologies in the processes of the geospatial information creation and processing. The constant increase of the information required amount and the reduction of decision-making time make it urgent to develop the military geoinformation system, that is an integral part of modern automated military and weapons control systems, and use them in planning and the control of the combat units of the Armed Forces.

Let's consider in more detail the functioning of the information systems at all levels headquarters and the possibility of accelerating the decision-making process with the introduction of automation control systems and digital geoinformation flows.

The process of the troop control in terms of information transmission and processing is divided into the number of successive stages (Fig. 1).

When performing the combat mission or during the sharp change in the situation that requires a fundamentally new decision, the commander and staff of the different levels organize the work in the following sequence. The full implementation of all the presented items is called the cycle of combat control. The staffs of all levels, except for the reception and transmission of information, must summarize it, process it, report to the higher staff, work out and draw up decisions and bring combat missions to the troops, followed by control over their implementation. Moreover, the information transmission by means of communication, taking into account its encryption and decryption is the minimum (in time) part of the combat control cycle.

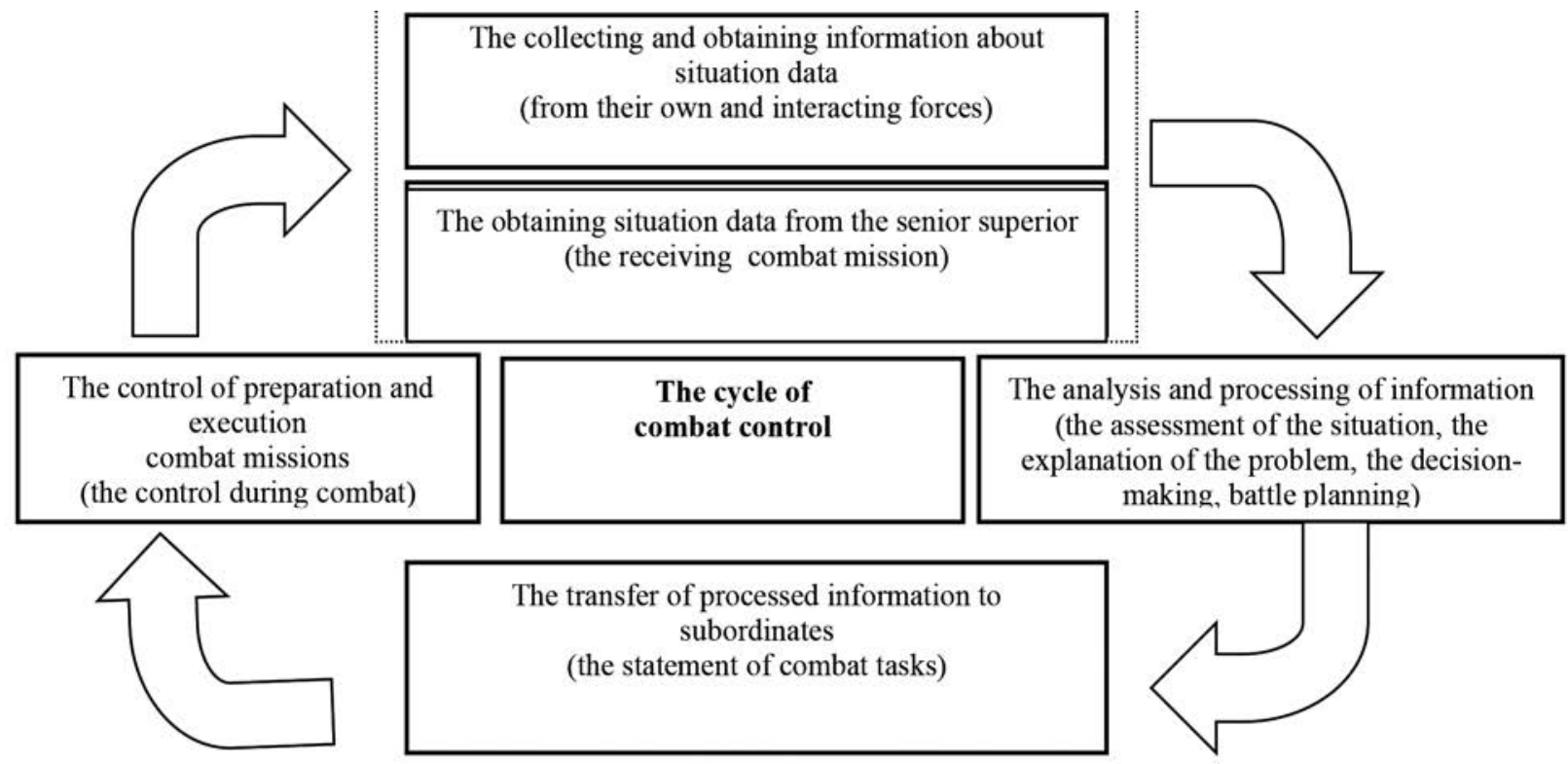

Fig. 1. The cycle of combat control from the standpoint of information transmission and processing.

All items shown in the figure are organizational and related to information processing. Only the direct preparation of the troops for combat missions is full of the practical measures that can't be minimized over time. Therefore, the real advantage over the enemy can be obtained only by reducing the time for information processing directly in the military authorities.

Currently, the process of situation reflecting is time-consuming. The reason is that information about the situation means little until it is presented in the user-friendly form, namely, graphically. This is especially true of the tactical level, where almost $90 \%$ of all incoming information is displayed in the form of the tactical signs.

The headquarters work essence of the displayed information is to convert incoming text and voice information into graphics (display on the map). The obtained information must be applied with high accuracy and in full, without "clogging" the topographic basis of the map. An experienced staff officer will determine, where his troops are, where the enemy is, what the task is, how the enemy plans to act, and so on in a very short time. That's why the map is the main working document in the headquarters of any level.

No less important point when the working with graphic information is that at least two or three scales of the topographic maps should be in almost any headquarters for planning and setting tasks. For example, when receiving the combat mission, the brigade works with topographic maps of at least three scales.

This is due to the need for simultaneous work of the brigade control officials with headquarters of different management levels. Thus, during the planning of the battle, the decision detailing of the brigade commander is 
usually two levels below. In addition to the elements of the subordinate's decisions, the decision map also includes data on the decisions of neighbors and interacting units.

With the different levels introduction of the geographic information systems in the governing bodies, the headquarters increasingly began to use electronic maps of the area. They are all represented by sets of files, that display individual sheets of the appropriate scales paper maps. Software "stitched" into a single array, these files form the area used by the headquarters as a topographic basis for the combat graphic documents working. Being exact copies of the ordinary maps, the electronic maps don't differ from them in nomenclature, scale and detail level. At the same time, differing in the degree of the objects detail, the electronic maps of different scales have a single coordinate system. Therefore, the tactical objects depicted on the electronic map at the scale of 1: 100,000 can be plotted on the electronic map at another scale. That is, the base scale for the tactical situation will be the scale of 1 : 100,000 and when you open the situation file on the electronic map at the scale of 1:50 000, all the characters will remain in the place. It should be taken into account, that with the increase in the scale of the electronic map will automatically increase in size exactly twice and tactical signs, completely closing the topographic basis of the map.

It follows, that when displaying the situation file on the large-scale map, it is necessary to change the basic scale of the situation, that's proportionally reduce all tactical signs until the size of the sign on the map approaches the size of the standard officer's stencil. And it is necessary to do it, reducing not each sign separately, and all situation as the whole. The modern geographic information systems, in turn, allow you to generalize images on the electronic map to the selected scale, taking into account the map basic scale.

The electronic maps make it possible to use in the brigade the single topographic basis with a through image of area objects (according to the selected scale) instead of three different topographic areas of the different detail paper topographic map.

How to implement it? The battalion commander, working in the local information network with subordinates, should be able to require them to provide files of their decisions through the network and organize access to these files for certain user's categories. As a result, he will have a real opportunity to see, how subordinates work, when applying the situation, and if necessary make adjustments, and subordinates - to see the situation of neighbors and when working out their decisions to take into account not only the task received from the battalion commander. It will allow already at the stage of the plan development to lay the foundations of interaction.

After clarifying the task, the situation assessing and the preliminary calculations made by the headquarters, the brigade commander must individually determine the plan and put it on the map. Based on the standards for processing and plotting on the map, usually it takes no more than an hour and a half. At the same time, the sooner the commander brings the plan to his deputies and chiefs of troops and services, the faster and better their proposals for the use of subordinate units and subdivisions will be worked out. It is especially important that the brigade management officials receive the design elements at the same time.

Without the automation use, the process of proving the idea becomes the series of the successive operations, because it is physically impossible to make several tracing papers at the same time. For example, in order to deploy artillery groups on the ground, it is necessary to know exactly the tasks and location of the general military units. Without knowing, where the all-military units and artillery will be located, it is impossible to determine the positions of air defense equipment. Without knowing the positions of air defense and artillery, it is impossible to determine the delivery routes of the missiles and ammunition, etc. In other words, until the commander decides on the plan, and the deputies and chiefs of the troops and services consistently issue them on the commander's card - the plan will not be issued in the amount necessary for further work.

Thus, there are two problems with the traditional approach to the headquarters work. The first concerns the display of the general military part of the plan on the map and bringing it to the brigade management officials. The second is related to mutual information of deputies and chiefs of troops and services about the content of their proposals graphic part of approved by the brigade commander.

In terms of the automation and use of the electronic maps, these problems can be solved by distributing the powers of the brigade officials to collect and sequence the application of the situation on the electronic map of the commander. To do this, in the local information network of the control point, taking into account the relevant distinctions of access rights, the principle of multi-user access to the files (layers) of the situation must be implemented, when each official sees all layers, but can apply (edit) the situation only in defined layers, without opportunities to change the situation in other layers. In this case, the brigade commander must have the right to make changes in any layer.

Now let's consider the possibility of setting combat tasks to subordinates in the visualized form and on an appropriate scale. The statement of combat tasks in the automated control system should be carried out in the following sequence: the battalion commander on the network receives a set of electronic administrative documents and the file with data about the enemy, the battalion's combat mission, the position of neighbors, etc. Having 
received this data, he organizes his work according to the classical scheme: clarifies the problem, assesses the situation, makes decisions, reports to his brigade commander, etc. In this case, all information exchange is carried out electronically through existing communication channels. After approval of the decision, he sets the task to the company commanders. At the same time the elements decisions of subordinates are put on the electronic map of the brigade commander in the brigade headquarter and the combat planning cycle comes to the end.

It can be argued that currently the automation of the processes and control tasks is directly related to the speed of the information collection and processing, its graphical design and data transmission of the situation [3]. An automated troop control system can provide this capability through unified subsystems that functionally complement each other. In this case, the functions of processing topo geodesic data using electronic maps of different scales and maintaining and displaying the operational situation will be technologically distributed between the geographic information subsystem and the subsystem of maintaining and displaying the position, the condition and actions of troops. It will allow the use of more efficient technologies for processing graphic information, and most importantly - to bring them as close as possible to the real needs of military authorities to develop plans, planning, organizing interaction, bringing tasks to the troops and monitoring their implementation.

The subsystem must have the built-in symbol designer, that will distribute the layers of the operational situation by officials, the levels of government, the armed services, the special forces, the combat service support, that ensures the rational distribution of collective work on the graphic documents, the organization of interaction, the exchange of information online, thereby solving all three problems of accelerating the decision-making process by the commander [4-5].

The solution to these problems is possible by designing and creating such software and hardware and special software, that will meet these requirements. The compliance with these requirements will minimize the cycle of combat control.

\section{Conclusions}

Thus, the essence of the military control automation will not only be in equipping troops with digital communications, especially in the purchase of expensive software and hardware, but in reducing the time to process information and automate those work performed by staff officers manually through implementation geoinformation and special information component in the military control process.

\section{References}

1. Koss V. An Information Model of the Armed Forces Management System as a Modern Type of Strategic Weapon. http://www.immsp.kiev.ua/perspages/koss_va/publ/13_statya_rpu.pdf.

2. Sinyavskiy V.K., Valahanovych P.A. Certain problems of automation of command and control processes and ways to solve them. Science and Military Security, 2012, p. 12-19.

3. Stuguk P.I, Grycay P.M., Voznuk U.S. World tendencies, problems and prospects of creation of automated systems of troops (forces) control. Proceedings of the Center for Military-Strategic Studies, 2012, 1(45), p. 68-76.

4. David DiBiase, Michael DeMers, Ann Johnson, Karen Kemp, Ann Taylor Luck, Brandon Plewe, Elizabeth Wentz. Geographic Information Science \& Technology. Body of Knowledge. Available: http://www.ucgis.org/.

5. Chornoknyzhnyi O. GIS experience in the US Armed Forces. Available: http://gis.sls.name/wp-content/ uploads/2015/01. 